\title{
Analysis of Selection Criteria of Purchasing Marine Engineering Equipment for Shipping and Shipbuilding Industries
}

\author{
Chun-Lien Su 1,a,*, Wen-Feng Chen ${ }^{1, b}$, Chi-Hsiang Liao, ${ }^{1, c}$, Wen-Fu Tu ${ }^{1, d}$, Hai-Ming Ching 1,e \\ ${ }^{1}$ Department of Marine Engineering, National Kaohsiung University of Science and Technology, \\ Kaohsiung City, Taiwan \\ a.cls@nkust.edu.tw; b.wf8925@gmail.com; c.chliao@nkust.edu.tw; d.twf@nkust.edu.tw; \\ e.hmsho@nkust.edu.tw \\ *corresponding author
}

Keywords: Marine Shipping Industry; Shipbuilding Industry; Marine Engineering; Selection Criteria; Shipbuilding Supply Chain.

Abstract: This paper aims to investigate the differences in evaluation and selection criteria affecting of procurement of marine equipment between marine shipping and shipbuilding industries. The multi-criteria decision-making of analytic hierarchy process (AHP) is used to develop the evaluation and selection model for procurement of marine equipment, and analyze the perception of such criteria in marine shipping and shipbuilding industries. In order to test the actual validity of the evaluation and selection model, this paper performed a validation study using actual data of marine shipping and shipbuilding industries. Test results have indicated that the top five most important criteria perceived by marine shipping industry were in the order including product quality standards, compliance with ship classification specifications, product reliability, product safety, and low population. The high largest perceptual differences between these two industries were in the order including product acquisition costs, vendor brand reputation, product quality standards, product reliability, and maintenance. The study results can be used as reference to reduce the perceptual differences between these two industries.

\section{Introduction}

At present, the shipbuilding and shipping industries of Taiwan are confronted with strong competitive pressure from international operations. In order to maintain the competitiveness and competitive advantage of the shipbuilding and shipping industries in Taiwan, suppliers must actively innovate products and upgrade quality, and use marine equipment acquisition strategies and cost reduction methods, so as to reduce operating costs and enhance the competitive advantage of the shipbuilding and shipping industries in the international market. In the present requirements for new shipbuilding facilities, the major pieces of marine equipment include marine diesel engines, steam turbines, gas turbines, generating sets, propeller shafting, screw propellers, main boilers, auxiliary 
boilers, deck machinery, steering systems, and auxiliary engines [1]. Europe, Japan and Korea possess a considerable market share for these marine equipment manufacturing technologies, especially in the aspect of marine turbine propelling power systems, and Europe remains predominant in professional design and technology.

Shipping and shipbuilding are upstream and downstream industries that supplement and promote each other. They have quite different industrial characteristics, but they have consistent requirements for marine equipment; there are some differences only in the purchasing aspect [2]. For one ship, the shipbuilding industry will purchase marine equipment at one time, whereas the shipping industry purchases marine equipment continuously. For example, the construction time for a container ship is about six months, and the dockyard will purchase marine equipment only once. However, the service life cycle of a general merchant ship is 25 to 30 years. As aging machines must be replaced, the shipping industry will purchase engine room equipment and parts continuously. The shipbuilding industry consists of profit-making enterprises, therefore cost and profit are always considered when purchasing marine equipment. However, the shipping industry is the end user of ships, therefore durability and operability are considered when purchasing marine equipment. Since the selection factors in purchasing marine equipment for the shipping and shipbuilding industries are different [3], it is necessary to establish selection criteria of the factors in purchasing marine equipment for the two suppliers and then analyze the differences.

This paper aims to investigate the differences in evaluation and selection criteria affecting of procurement of marine equipment between marine shipping and shipbuilding industries. The multicriteria decision-making (MCDM) of analytic hierarchy process (AHP) is used to develop the evaluation and selection model for procurement of marine equipment, and analyzed the perception of such criteria in marine shipping and shipbuilding industries. In order to test the actual validity of the evaluation and selection model, this paper performed a validation study using actual data of marine shipping and shipbuilding industries. The analytical model and method used in this paper and the questionnaire survey analysis results are introduced in detail in the following sections.

\section{Influential Factors in Selection of Marine Equipment Procurement}

In the shipbuilding and shipping supply chain systems, the evaluation and selection of marine equipment industries are very important. In supply chain management, the analysis of selection criteria is important for screening and establishing the selection criteria of purchasing marine equipment products. First the index of the selection criteria of purchasing marine equipment is established. As the shipbuilding and shipping industries have special characteristics, the selection factors are established by referring to domestic and foreign references, as well as the expert advice of the shipbuilding and shipping industries in Taiwan.

For the selection criteria of marine equipment procurement, the quantitative and qualitative factors were considered in order to reflect the actual conditions of shipbuilding and shipping industries. This paper reviews the marine engineering equipment functions reported in [4] and refers the concept of purchasing and supply chain management in [5] and expert advice of shipbuilding and shipping industries in Taiwan to determine the key factors in the selection criteria of purchasing marine equipment products. The study results of key factors are shown in Table I.

As can be seen from Table I, the selection criteria considered in this paper are divided into four major dimensions and 20 key factors, including: 1) the price cost dimension, including fuel energy consumption, low maintenance cost, low installation cost, product transportation cost, and product purchase cost; 2) the brand quality dimension, including low pollution high efficiency energy savings, product quality level, meeting classification regulations, low vibration, low noise, and the manufacturer's brand reputation; 3 ) the global service dimension, including global service networks, 
training service, sustainable parts supplies, product assurance ability, and after-sales maintenance service; and 4) the design performance dimension, including equipment controllability, maintainability, equipment reliability, equipment safety, and equipment functionality.

\section{Solution Method}

For the selection of an option, the traditional practice takes cost minimization or benefit maximization as the goal of decision making. However, in practice, most decision problems have multiple criteria, and the criteria may have conflicts, therefore the decision result of one single index is too narrow. In addition, various criteria are unlikely to have the same unit of analysis. In this situation, the MCDM technique is required for evaluation, to avoid considering multiple options in only one direction, and allowing they decision making result to be more correct and reasonable [6,7].

Generally speaking, MCDM problems can be divided into discrete and continuous types [8], according to the characteristics of the decision-making scheme. The discrete MCDM problem usually selects the optimal scheme from a group of schemes. The continuous MCDM problem is usually represented by a mathematical equation that is used to find the optimal solution, e.g. multi-objective linear programming. The problem studied in this paper is a discrete MCDM problem. The common method for analyzing this type of problem is AHP, therefore the AHP theory described in [9] is used in this paper to analyze the factors influencing the selection of marine equipment procurement. The computation procedure of the proposed method is that first, the problem is described, the influential factors are found out and the hierarchical relationship is established, and then the questionnaire is designed. Based on the survey data, the relative importance of the decision attributes of various hierarchies is found according to the ratio scale by pairwise comparison. The pairwise comparison matrix is established and the eigenvalue and eigenvector of the matrix are calculated. The consistency of the analysis results is tested and the weightings of various attributes are calculated so as to determine the optimal option or combination.

This paper uses AHP to build multiple criteria decision-making hierarchies according to the analyses of the various dimensions shown in Table I. There are three hierarchies considered in this paper. Hierarchy 1 is the goal level, including the differences in the factors influencing the selection of marine equipment procurement for shipping and shipbuilding industries. Hierarchy 2 is the four major dimensions of the selection criteria for marine equipment procurement. Hierarchy 3 has 20 attribute element layers under the four major dimensions, in which the elements of each hierarchy are assumed to be independent of each other. In terms of the questionnaire survey, according to the hierarchical element architecture established in Table I, this paper establishes an AHP expert questionnaire, including the questionnaire of the Hierarchy 2 selection dimension and the questionnaire of the Hierarchy 3 selection criteria. For pairwise comparison of the relative importance between pairwise criteria, in the questionnaire designed by this paper, each evaluation factor criterion is divided into nine importance classes for pairwise comparison, as shown in Table II.

\section{Test Results and Discussion}

This paper takes the shipping and shipbuilding industries of Taiwan as research parents, and the questionnaire respondents are divided into the turbine personnel on the shipbuilding side and the shipping side. A total of 30 persons are selected randomly from the shipbuilding industry and the shipping industry according to the member lists of the Taiwan Shipbuilding Industry Association, and they are contacted to ask if they are willing to fill out the questionnaire, until the predetermined number of samples is reached. The profiles of the respondents are the managers and engineers in charge for related marine engineering departments in shipbuilding and shipping companies in Taiwan. Since the space is limited, the details for the respondents can be found from [10]. 
Table 1: The Proposed Selection Criteria of Marine Equipment Procurement

\begin{tabular}{|c|c|}
\hline Purposes & Evaluation criteria \\
\hline \multirow{5}{*}{ A:Price cost } & A1: Fuel energy consumption \\
\hline & A2: Low maintenance cost \\
\hline & A3: Lower installation cost \\
\hline & A4: Product transportation cost \\
\hline & A5: Product acquisition cost \\
\hline \multirow{5}{*}{$\begin{array}{l}\text { B: Quality } \\
\text { brand }\end{array}$} & $\begin{array}{l}\text { B1: Low pollution high efficiency } \\
\text { energy saving }\end{array}$ \\
\hline & B2: Product quality level \\
\hline & B3: Meet classification specification \\
\hline & B4: Low vibration low noise \\
\hline & B5: Manufacturer's brand reputation \\
\hline \multirow{5}{*}{$\begin{array}{l}\text { C: Global } \\
\text { service }\end{array}$} & C1: Global service network \\
\hline & C2: Training service \\
\hline & C3: Sustainable supply of parts \\
\hline & C4: Product assurance ability \\
\hline & C5: After-sales maintenance service \\
\hline \multirow{5}{*}{$\begin{array}{c}\text { D: Design } \\
\text { performance }\end{array}$} & D1: Product controllability \\
\hline & D2: Maintainability \\
\hline & D3: Product reliability \\
\hline & D4: Product safety \\
\hline & D5: Product functionality \\
\hline
\end{tabular}

Table 2: Definition and Description of Evaluation Criteria

\begin{tabular}{|c|l|l|}
\hline $\begin{array}{c}\text { Evaluation } \\
\text { scale }\end{array}$ & \multicolumn{1}{|c|}{ Definition } & \multicolumn{1}{c|}{ Description } \\
\hline 1 & Equal importance & Two factors have equal importance \\
\hline 3 & Weak importance & $\begin{array}{l}\text { Experience and judgment slightly } \\
\text { prefer a scheme }\end{array}$ \\
\hline 5 & Essential importance & $\begin{array}{l}\text { Experience and judgment strongly } \\
\text { prefer a scheme }\end{array}$ \\
\hline 7 & Very strong importance & $\begin{array}{l}\text { Experience and judgment very } \\
\text { strongly prefer a scheme }\end{array}$ \\
\hline 9 & Absolute importance & $\begin{array}{l}\text { Enough evidence for absolute } \\
\text { preference for a scheme }\end{array}$ \\
\hline $2,4,6,8$ & $\begin{array}{l}\text { Intermediate value of } \\
\text { adjacent scales }\end{array}$ & When trade-off value required \\
\hline
\end{tabular}

This study interviews 30 persons from the shipbuilding industry and 30 persons from the shipping industry, for a total of 60 persons. First, the consistency test is implemented for the 60 samples using AHP method, and 10 samples do not pass the test. The consistency index (C.I.) and the consistency ratio (C.R.) are higher than 0.1 , so there are 50 valid samples obtained eventually, including 25 from the shipbuilding industry and 25 from the shipping industry. The consistency test results are shown in Tables III and IV, where the $\lambda_{\max }$ is the maximum eigenvalue. According to the suggestion of AHP, 
the appropriate number of group decision experts is five to fifteen, therefore the questionnaire survey of this paper is representative to some extent. Table V shows that the C.I. and C.R. values of all questionnaires are smaller than 0.1. This test result shows that the 50 sample data meet the consistency test, meaning the respondents have a high consistency of pairwise comparisons of various hierarchies, and the consistency of the criteria pairwise comparison matrix is reliable.

Table 3: Consistency Analysis Results of Various Hierarchies in Questionnaires Received from the Shipbuilding Industry

\begin{tabular}{|c|c|c|c|c|c|c|c|c|c|c|c|c|c|c|c|}
\hline \multirow[t]{2}{*}{$\begin{array}{c}\text { Questionnaire } \\
\text { No. }\end{array}$} & \multicolumn{3}{|c|}{$\begin{array}{c}\text { Goal level } \\
\text { nए } 4\end{array}$} & \multicolumn{3}{|c|}{$\begin{array}{c}\text { Dimension level A } \\
\text { (price cost) } \\
\text { n } 55\end{array}$} & \multicolumn{3}{|c|}{$\begin{array}{c}\text { Dimension level B } \\
\text { (quality brand) } \\
\mathrm{n} \square 5\end{array}$} & \multicolumn{3}{|c|}{$\begin{array}{c}\text { Dimension level C } \\
\text { (global service) } \\
\text { nए } 5\end{array}$} & \multicolumn{3}{|c|}{$\begin{array}{c}\text { Dimension level D } \\
\text { (design performance) } \\
\mathrm{n} \square 5\end{array}$} \\
\hline & $\lambda_{\max }$ & C.I. & C.R. & $\lambda_{\max }$ & C.I. & C.R. & $\lambda_{\max }$ & C.I. & C.R. & $\lambda_{\max }$ & C.I. & C.R. & $\lambda_{\max }$ & C.I. & C.R. \\
\hline 1 & 4.15 & 0.05 & 0.06 & 5.08 & 0.02 & 0.02 & 5.08 & 0.02 & 0.02 & 5.16 & 0.04 & 0.04 & 5.16 & 0.04 & 0.04 \\
\hline 2 & 4.00 & 0.00 & 0.00 & 5.28 & 0.07 & 0.06 & 5.20 & 0.05 & 0.05 & 5.32 & 0.08 & 0.07 & 5.20 & 0.05 & 0.05 \\
\hline 3 & 4.06 & 0.02 & 0.02 & 5.28 & 0.07 & 0.06 & 5.32 & 0.08 & 0.07 & 5.36 & 0.09 & 0.08 & 5.12 & 0.03 & 0.03 \\
\hline 4 & 4.03 & 0.01 & 0.01 & 5.04 & 0.01 & 0.01 & 5.28 & 0.07 & 0.06 & 5.36 & 0.09 & 0.08 & 5.36 & 0.09 & 0.08 \\
\hline 5 & 4.18 & 0.06 & 0.07 & 5.36 & 0.09 & 0.08 & 5.36 & 0.09 & 0.08 & 5.20 & 0.05 & 0.05 & 5.36 & 0.09 & 0.08 \\
\hline 6 & 4.12 & 0.04 & 0.04 & 5.36 & 0.09 & 0.08 & 5.36 & 0.09 & 0.08 & 5.32 & 0.08 & 0.07 & 5.24 & 0.06 & 0.05 \\
\hline 7 & 4.06 & 0.02 & 0.02 & 5.12 & 0.03 & 0.03 & 5.08 & 0.02 & 0.02 & 5.00 & 0.00 & 0.00 & 5.04 & 0.01 & 0.01 \\
\hline 8 & 4.12 & 0.04 & 0.04 & 5.36 & 0.09 & 0.08 & 5.36 & 0.09 & 0.08 & 5.16 & 0.04 & 0.04 & 5.36 & 0.09 & 0.08 \\
\hline 9 & 4.06 & 0.02 & 0.02 & 5.04 & 0.01 & 0.01 & 5.28 & 0.07 & 0.06 & 5.04 & 0.01 & 0.01 & 5.08 & 0.02 & 0.02 \\
\hline 10 & 4.24 & 0.08 & 0.09 & 5.28 & 0.07 & 0.06 & 5.28 & 0.07 & 0.06 & 5.16 & 0.04 & 0.04 & 5.16 & 0.04 & 0.04 \\
\hline 11 & 4.06 & 0.02 & 0.02 & 5.04 & 0.01 & 0.01 & 5.04 & 0.01 & 0.01 & 5.04 & 0.01 & 0.01 & 5.04 & 0.01 & 0.01 \\
\hline 12 & 4.06 & 0.02 & 0.02 & 5.08 & 0.02 & 0.02 & 5.24 & 0.06 & 0.05 & 5.12 & 0.03 & 0.03 & 5.24 & 0.06 & 0.05 \\
\hline 13 & 4.18 & 0.06 & 0.07 & 5.12 & 0.03 & 0.03 & 5.00 & 0.00 & 0.00 & 5.16 & 0.04 & 0.04 & 5.00 & 0.00 & 0.00 \\
\hline 14 & 4.15 & 0.05 & 0.06 & 5.32 & 0.08 & 0.07 & 5.32 & 0.08 & 0.07 & 5.12 & 0.03 & 0.03 & 5.32 & 0.08 & 0.07 \\
\hline 15 & 4.21 & 0.07 & 0.08 & 5.32 & 0.08 & 0.07 & 5.20 & 0.05 & 0.05 & 5.24 & 0.06 & 0.05 & 5.12 & 0.03 & 0.03 \\
\hline 16 & 4.03 & 0.01 & 0.01 & 5.24 & 0.06 & 0.05 & 5.20 & 0.05 & 0.05 & 5.12 & 0.03 & 0.03 & 5.32 & 0.08 & 0.07 \\
\hline 17 & 4.12 & 0.04 & 0.04 & 5.08 & 0.02 & 0.02 & 5.04 & 0.01 & 0.01 & 5.04 & 0.01 & 0.01 & 5.04 & 0.01 & 0.01 \\
\hline 18 & 4.00 & 0.00 & 0.00 & 5.08 & 0.02 & 0.02 & 5.12 & 0.03 & 0.03 & 5.04 & 0.01 & 0.01 & 5.08 & 0.02 & 0.02 \\
\hline 19 & 4.24 & 0.08 & 0.09 & 5.28 & 0.07 & 0.06 & 5.20 & 0.05 & 0.05 & 5.32 & 0.08 & 0.07 & 5.24 & 0.06 & 0.05 \\
\hline 20 & 4.09 & 0.03 & 0.03 & 5.16 & 0.04 & 0.04 & 5.16 & 0.04 & 0.04 & 5.12 & 0.03 & 0.03 & 5.32 & 0.08 & 0.07 \\
\hline 21 & 4.21 & 0.07 & 0.08 & 5.20 & 0.05 & 0.05 & 5.12 & 0.03 & 0.03 & 5.12 & 0.03 & 0.03 & 5.12 & 0.03 & 0.03 \\
\hline 22 & 4.18 & 0.06 & 0.07 & 5.16 & 0.04 & 0.04 & 5.08 & 0.02 & 0.02 & 5.12 & 0.03 & 0.03 & 5.08 & 0.02 & 0.02 \\
\hline 23 & 4.18 & 0.06 & 0.07 & 5.28 & 0.07 & 0.06 & 5.28 & 0.07 & 0.06 & 5.32 & 0.08 & 0.07 & 5.00 & 0.00 & 0.00 \\
\hline 24 & 4.00 & 0.00 & 0.00 & 5.36 & 0.09 & 0.08 & 5.08 & 0.02 & 0.02 & 5.12 & 0.03 & 0.03 & 5.00 & 0.00 & 0.00 \\
\hline 25 & 4.15 & 0.05 & 0.06 & 5.16 & 0.04 & 0.04 & 5.32 & 0.08 & 0.07 & 5.16 & 0.04 & 0.04 & 5.04 & 0.01 & 0.01 \\
\hline
\end{tabular}


Table 4: Consistency Analysis Results of Various Hierarchies in Questionnaires Recieved From the Shipping Industry

\begin{tabular}{|c|c|c|c|c|c|c|c|c|c|c|c|c|c|c|c|}
\hline \multirow[t]{2}{*}{$\begin{array}{c}\text { Questionnaire } \\
\text { No. }\end{array}$} & \multicolumn{3}{|c|}{$\begin{array}{c}\text { Goal level } \\
\text { n口 } 4\end{array}$} & \multicolumn{3}{|c|}{$\begin{array}{l}\text { Dimension level A } \\
\text { (price cost) } \\
\text { n } 55\end{array}$} & \multicolumn{3}{|c|}{$\begin{array}{c}\text { Dimension level B } \\
\text { (quality brand) } \\
\mathrm{n} \square 5\end{array}$} & \multicolumn{3}{|c|}{$\begin{array}{c}\text { Dimension level C } \\
\text { (global service) } \\
\text { nए } 5\end{array}$} & \multicolumn{3}{|c|}{$\begin{array}{c}\text { Dimension level D } \\
\text { (design performance) } \\
\mathrm{n} \square 5\end{array}$} \\
\hline & $\lambda_{\max }$ & C.I. & C.R. & $\overline{\lambda_{\max }}$ & C.I. & C.R. & $\lambda_{\max }$ & C.I. & C.R. & $\lambda_{\max }$ & C.I. & C.R. & $\lambda_{\max }$ & C.I. & C.R. \\
\hline 1 & 4.15 & 0.05 & 0.06 & 5.16 & 0.04 & 0.04 & 5.32 & 0.08 & 0.07 & 5.20 & 0.05 & 0.05 & 5.32 & 0.08 & 0.07 \\
\hline 2 & 4.12 & 0.04 & 0.04 & 5.32 & 0.08 & 0.07 & 5.16 & 0.04 & 0.04 & 5.16 & 0.04 & 0.04 & 5.04 & 0.01 & 0.01 \\
\hline 3 & 4.09 & 0.03 & 0.03 & 5.20 & 0.05 & 0.05 & 5.32 & 0.08 & 0.07 & 5.36 & 0.09 & 0.08 & 5.24 & 0.06 & 0.05 \\
\hline 4 & 4.21 & 0.07 & 0.08 & 5.16 & 0.04 & 0.04 & 5.08 & 0.02 & 0.02 & 5.00 & 0.00 & 0.00 & 5.20 & 0.05 & 0.05 \\
\hline 5 & 4.18 & 0.06 & 0.07 & 5.28 & 0.07 & 0.06 & 5.28 & 0.07 & 0.06 & 5.32 & 0.08 & 0.07 & 5.28 & 0.07 & $\overline{0.06}$ \\
\hline 6 & 4.18 & 0.06 & 0.07 & 5.32 & 0.08 & 0.07 & 5.24 & 0.06 & 0.05 & 5.20 & 0.05 & 0.05 & 5.12 & 0.03 & 0.03 \\
\hline 7 & 4.12 & 0.04 & 0.04 & 5.32 & 0.08 & 0.07 & 5.36 & 0.09 & 0.08 & 5.24 & 0.06 & 0.05 & 5.32 & 0.08 & 0.07 \\
\hline 8 & 4.06 & 0.02 & 0.02 & 5.36 & 0.09 & 0.08 & 5.32 & 0.08 & 0.07 & 5.28 & 0.07 & 0.06 & 5.36 & 0.09 & 0.08 \\
\hline 9 & 4.12 & 0.04 & 0.04 & 5.32 & 0.08 & 0.07 & 5.32 & 0.08 & 0.07 & 5.16 & 0.04 & 0.04 & 5.04 & 0.01 & 0.01 \\
\hline 10 & 4.15 & 0.05 & 0.06 & 5.12 & 0.03 & 0.03 & 5.28 & 0.07 & 0.06 & 5.24 & 0.06 & 0.05 & 5.20 & 0.05 & 0.05 \\
\hline 11 & 4.00 & 0.00 & 0.00 & 5.36 & 0.09 & 0.08 & 5.20 & 0.05 & 0.05 & 5.24 & 0.06 & 0.05 & 5.28 & 0.07 & 0.06 \\
\hline 12 & 4.15 & 0.05 & 0.06 & 5.36 & 0.09 & 0.08 & 5.36 & 0.09 & 0.08 & 5.24 & 0.06 & 0.05 & 5.32 & 0.08 & 0.07 \\
\hline 13 & 4.15 & 0.05 & 0.06 & 5.32 & 0.08 & 0.07 & 5.36 & 0.09 & 0.08 & 5.32 & 0.08 & 0.07 & 5.36 & 0.09 & 0.08 \\
\hline 14 & 4.21 & 0.07 & 0.08 & 5.36 & 0.09 & 0.08 & 5.28 & 0.07 & 0.06 & 5.36 & 0.09 & 0.08 & 5.24 & 0.06 & 0.05 \\
\hline 15 & 4.09 & 0.03 & 0.03 & 5.28 & 0.07 & 0.06 & 5.32 & 0.08 & 0.07 & 5.20 & 0.05 & 0.05 & 5.20 & 0.05 & 0.05 \\
\hline 16 & 4.09 & 0.03 & 0.03 & 5.36 & 0.09 & 0.08 & 5.32 & 0.08 & 0.07 & 5.24 & 0.06 & 0.05 & 5.36 & 0.09 & 0.08 \\
\hline 17 & 4.27 & 0.09 & 0.09 & 5.28 & 0.07 & 0.06 & 5.12 & 0.03 & 0.03 & 5.28 & 0.07 & 0.06 & 5.32 & 0.08 & 0.07 \\
\hline 18 & 4.06 & 0.02 & 0.02 & 5.16 & 0.04 & 0.04 & 5.20 & 0.05 & 0.05 & 5.28 & 0.07 & 0.06 & 5.00 & 0.00 & $\overline{0.00}$ \\
\hline 19 & 4.27 & 0.09 & 0.09 & 5.32 & 0.08 & 0.07 & 5.20 & 0.05 & 0.05 & 5.08 & 0.02 & 0.02 & 5.12 & 0.03 & 0.03 \\
\hline 20 & 4.18 & 0.06 & 0.07 & 5.32 & 0.08 & 0.07 & 5.20 & 0.05 & 0.05 & 5.20 & 0.05 & 0.05 & 5.24 & 0.06 & 0.05 \\
\hline 21 & 4.15 & 0.05 & 0.06 & 5.16 & 0.04 & 0.04 & 5.16 & 0.04 & 0.04 & 5.16 & 0.04 & 0.04 & 5.16 & 0.04 & 0.04 \\
\hline 22 & 4.03 & 0.01 & 0.01 & 5.08 & 0.02 & 0.02 & 5.04 & 0.01 & 0.01 & 5.24 & 0.06 & 0.05 & 5.00 & 0.00 & 0.00 \\
\hline 23 & 4.21 & 0.07 & 0.08 & 5.32 & 0.08 & 0.07 & 5.24 & 0.06 & 0.05 & 5.20 & 0.05 & 0.05 & 5.20 & 0.05 & 0.05 \\
\hline 24 & 4.03 & 0.01 & 0.01 & 5.04 & 0.01 & 0.01 & 5.00 & 0.00 & 0.00 & 5.00 & 0.00 & 0.00 & 5.00 & 0.00 & 0.00 \\
\hline 25 & 4.09 & 0.03 & 0.03 & 4.00 & 0.00 & 0.00 & 5.00 & 0.00 & 0.00 & 5.00 & 0.00 & 0.00 & 5.00 & 0.00 & $\overline{0.00}$ \\
\hline
\end{tabular}

Table 5: Consistency Test Results

\begin{tabular}{|c|c|c|c|c|c|}
\hline $\begin{array}{c}\text { Industry } \\
\text { investigated }\end{array}$ & \multirow{2}{*}{\multicolumn{2}{|c|}{ Level category }} & C.I. & R.I. & C.R. \\
\hline (Qty) & & & & & \\
\hline \multirow{5}{*}{$\begin{array}{l}\text { Shipbuilding } \\
\text { industry }\end{array}$} & \multicolumn{2}{|c|}{ Goal level } & 0.00306 & 0,0625 & 0.00340 \\
\hline & \multirow{4}{*}{ Dimension level } & Price cost & 0.00084 & 01.12 & 0.00075 \\
\hline & & $\begin{array}{l}\text { Quality } \\
\text { brand }\end{array}$ & 0.00313 & 01.12 & 0.00279 \\
\hline & & $\begin{array}{l}\text { Global } \\
\text { service }\end{array}$ & 0.00210 & 01.12 & 0.00188 \\
\hline & & $\begin{array}{c}\text { Design } \\
\text { performance }\end{array}$ & 0.00087 & 01.12 & 0.00078 \\
\hline \multirow{5}{*}{$\begin{array}{l}\text { Shipping } \\
\text { industry }\end{array}$} & \multicolumn{2}{|c|}{ Goal level } & 0.00002 & 0,0625 & 0.00002 \\
\hline & \multirow{4}{*}{ Dimension level } & Price cost & 0.00873 & 01.12 & 0.00779 \\
\hline & & $\begin{array}{l}\text { Quality } \\
\text { brand }\end{array}$ & 0.00575 & 01.12 & 0.00513 \\
\hline & & $\begin{array}{l}\text { Global } \\
\text { service }\end{array}$ & 0.00477 & 01.12 & 0.00426 \\
\hline & & $\begin{array}{c}\text { Design } \\
\text { performance }\end{array}$ & 0.00243 & 01.12 & 0.00217 \\
\hline
\end{tabular}


The differences between the shipbuilding and shipping industries in the selection criteria are analyzed and shown in Figs. 1 and 2. It can be seen from Figs. 1 and 2 that the respondents from the shipbuilding industry identify meeting classification specifications as the most important, followed by product acquisition cost, product quality level, product safety, and manufacturer's brand reputation. The respondents from the shipping industry identify product quality level as the most important, followed by meeting classification specification, product reliability, product safety, and low pollution high efficiency energy savings. The test results also indicate that the supplier and demander of the shipbuilding industry and shipping industry have generally different importance rankings for the selection criteria and requirements for the selection criteria of purchasing marine equipment, but the same importance ranking for low maintenance cost, low vibration low noise, and product safety. The respondents from the shipbuilding industry indicate that meeting classification specifications is important, whereas the respondents from the shipping industry indicate that product quality level is important. However, the shipbuilding industry and the shipping industry both indicate that meeting classification specifications and product quality level are important factors, and they regard training service, global service networks, and product transportation cost as less important factors.

The comparison analysis of the cognition gaps in the dimensions and elements of the shipbuilding and shipping sides is also performed. The test results show that, the cognition gaps of the dimension selection are the price cost dimension (the shipbuilding industry pays more attention to the price cost dimension than the shipping industry, and the cognition difference is 9.00\%); the brand quality dimension (the shipping industry pays more attention to the brand quality dimension than the shipbuilding industry, and the cognition difference is $-2.50 \%$ ); the global service dimension (the shipbuilding industry pays more attention to the global service dimension than the shipping industry, and the cognition difference is $0.50 \%$ ); and the design performance dimension (the shipping industry pays more attention to the design performance dimension than the shipbuilding industry, and the cognition difference is $-7.00 \%$ ). The analysis results indicate that, in terms of dimension cognition, the shipbuilding industry pays close attention to price cost and global service dimensions, while the shipping industry pays close attention to design performance and brand quality dimensions. The test result also shows the ranking of the top 10 element selection cognition gaps, which are the product acquisition cost, manufacturer's brand reputation, product quality level, product reliability, maintainability, low pollution high efficiency energy savings, low installation cost, product transportation cost, global service network, fuel energy consumption. The cognition difference gaps are $7.13 \%, 3.71 \%,-3.54 \%,-3.30 \%,-2.39 \%,-1.84 \%, 1.66 \%, 1.06 \%, 0.95 \%$ and $-0.81 \%$, respectively. The analysis result shows that, in terms of element cognition, the shipbuilding industry pays close attention to product acquisition cost, manufacturer's brand reputation, low installation cost, product transportation cost and global service networks, while the shipping industry pays close attention to product quality level, product reliability, maintainability, low pollution high efficiency energy savings, and fuel energy consumption. 


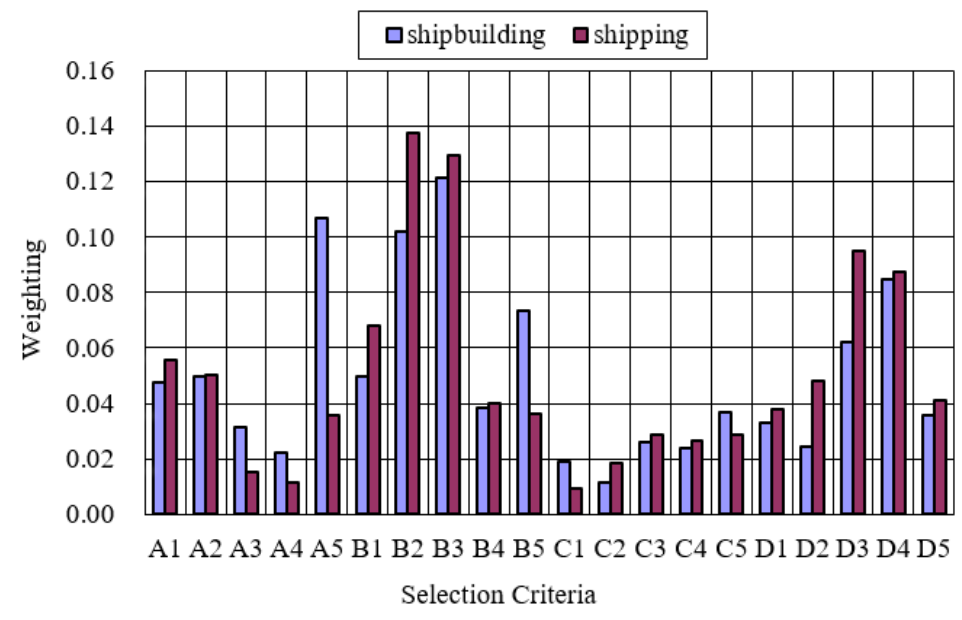

Figure 1: Weighting differences in the selection criteria of the shipping and shipbuilding industries

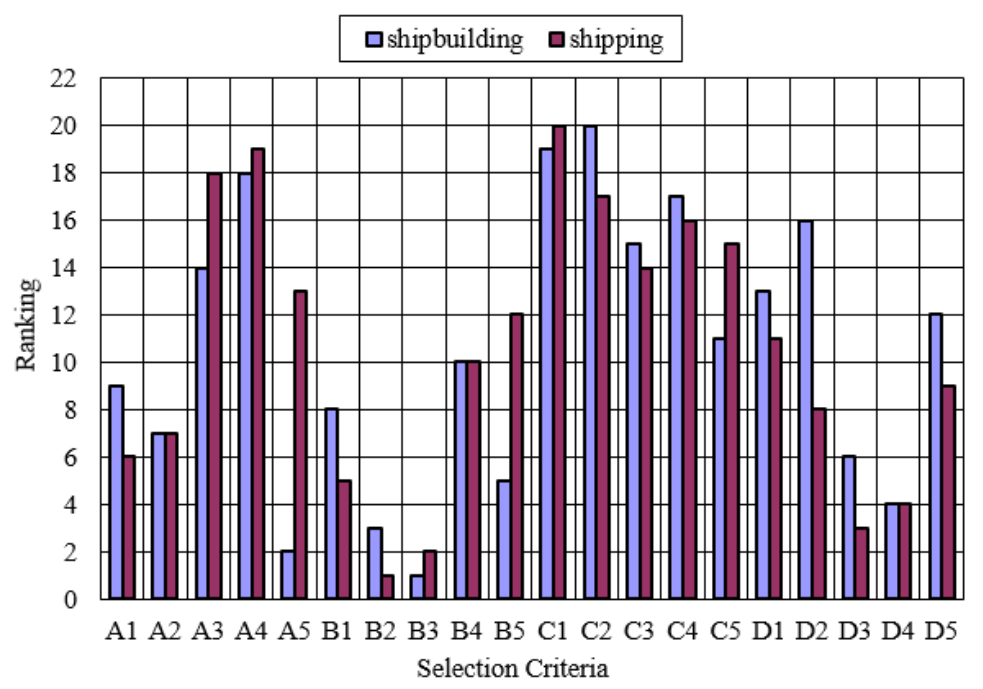

Figure 2: Ranking differences in the selection criteria of the shipping and shipbuilding industries

\section{Conclusions}

An analytic hierarchy process theory based multi-criteria decision-making model for the differences in the factors influencing the selection of marine equipment procurement for the shipping and shipbuilding industries has been proposed. A hierarchical architecture of four major dimensions and 20 selection criteria which influence the selection of purchasing marine equipment for the shipping and shipbuilding industries has been built. The consistency test and analytic hierarchy process comparative approach have been used to confirm the questionnaire survey data validity and calculate the weighting and ranking of various dimensions and elements. The test results indicate that the elements of the top five weightings of the shipbuilding industry are meeting classification specifications, product acquisition cost, product quality level, product safety, and manufacturer's brand reputation. The elements of the top five weightings of the shipping industry are product quality level, meeting classification specifications, product reliability, product safety, and low pollution high efficiency energy savings. With the analysis results, the shipbuilding industry can identify the problems in the shipping customer requirements and eliminate the cognition difference gaps of both sides, so as to enhance and accelerate the cooperation of shipbuilding supply chain systems. 


\section{References}

[1] D. A. Taylor, Introduction to Marine Engineering, Elsevier Ltd., 1996.

[2] Global Marine Trends 2030. [Online]. Available: http://www.maritimeindustries.org/write/ Uploads/News/2013/2nd\%20Quarter/Global_Marine_Trends_2030_Brochure.pdf.

[3] Marine Procurement. [Online]. Available: http://www.bctq.com/marine-procurement.asp.

[4] R. L. Harrington, Marine Engineering, The Society of Naval Architects and Marine Engineers, 1992.

[5] K. Lysons and B. Farrington, Purchasing and Supply Chain Management (9th ed.), Pearson Education Ltd., 2016.

[6] G. Cunha, J. C. Ferreira, J. A. Covas, and G. Recio, "Selection of solutions in multi-objective optimization: decision making and robustness, " in Proc. 2014 IEEE Symposium on Computational Intelligence in Multi-Criteria DecisionMaking.

[7] J. F. Agwa-Ejon, A. Mulaba-Bafubiandi, and J. H. Pretorius, " The multi-criteria decision making, a tool for the promotion of technological inter-connected world through digital decision making," in Proc. 2017 Portland International Conference on Management of Engineering and Technology.

[8] E. Triantaphyllou, B. Shu, S. N. Sanchez, and T. Ray, "Multi-criteria decision making: an operations research approach," in Encyclopedia of Electrical and Electronics Engineering, J. G. Webster, Ed., New York: John Wiley \& Sons, 1998, pp. 175-186.

[9] T. L. Saaty and L. G. Vargas, Decision Making with the Analytic Network Process: Economic, Political, Social and Technological Applications with Benefits, Opportunities, Costs and Risks, Springer Science+Business Media LLC, 2013.

[10] W. F. Chen, "A study on the difference analysis of selection criteria of purchasing marine engineering equipment for shipping and shipbuilding industries," M.S. Thesis submitted for National Kaohsiung Marine University, Taiwan, July 2017. 